\title{
Intergroup Dissimilarity Predicts Physiological Synchrony and Affiliation in Intergroup Interaction
}

\author{
Chad Danyluck and Elizabeth Page-Gould \\ Department of Psychology, University of Toronto, Ontario
}

6882 words

\section{Author Note}

This research was funded by a Social Sciences and Humanities Research Council of Canada (SSHRC) doctoral fellowship awarded to the first author and a SSHRC Standard Research Grant awarded to the second author. We are also grateful to the research assistants who helped with data collection and various stages of data processing: Michelle Atsu, Tahmina Aziz, Veerpal Bambrah, Mark Berridge, Jairo Caceres, Angela Chung, Shweta Dhawan, Divya Gossai, Denis Kilinç, Ling Lam, Tracie Marryshow, Satmeen Nagra, Daniel Potter, Matthew Quitasol, Zaini Sarwar, Julian Scheffer, Lilian Thai, and Alexander Vadakojis. We also thank James

Climenhage, Sarah Ghorpade, Bonnie Le, Robert Levenson, Richard Palumbo, Sheryl Stevenson, and Shelly Zhou for comments and discussions that contributed to this manuscript. This research was conducted as part of the first author's Master Thesis.

Correspondence concerning this article should be addressed to Chad Danyluck, Department of Psychology, University of Toronto, Toronto, ON, M5S 3 G3.

Email: chad.danyluck@mail.utoronto.ca 


\begin{abstract}
Interpersonal similarity attracts. In intergroup contexts, however, similarity between groups potentiates bias. The current study examined whether intergroup similarity versus dissimilarity engenders cross-group friendship formation. We used an essay-writing paradigm to manipulate perceived intergroup similarity or dissimilarity between the ethnic groups of participants prior to a dyadic interaction that involved a competitive party game. During the interaction, we continuously recorded physiological and behavioral responses from both participants. We used the physiological responses to derive a measure of physiological synchrony: the mutual activation of partners' sympathetic nervous systems. People primed with dissimilarity, not similarity, experienced physiological synchrony with their partner. Moreover, the partners of people primed with dissimilarity acted more affiliative than the partners of people primed with similarity, which in turn predicted friendship initiation by participants. We discuss the seemingly counter-intuitive value of emphasizing differences between groups to foster positive intergroup relations.
\end{abstract}

Keywords: intergroup similarity, cross-group friendship, social interactions, physiological synchrony, sympathetic nervous system 


\section{Intergroup Dissimilarity Predicts Physiological Synchrony and Affiliation in Intergroup Interaction}

Social identity theory posits that similarity between social groups can trigger animosity and intergroup conflict (Brewer, 1991; Leonardelli, Pickett, \& Brewer, 2010; Tajfel, 1978). The basis of such animosity is a motivation to restore or amplify the distinctiveness of the social groups to which a person belongs ("ingroups") relative to the social groups to which a person does not belong ("outgroups"). Having a sense of positive distinctiveness relative to a comparison outgroup enables people to gain positive self-esteem from their social identities. Hence, when similarity between groups undermines distinctiveness, the drive to feel good about oneself can give rise to behaviors and judgements that create social distance between groups and may sour intergroup relationships.

Despite decades of research examining how intergroup similarity elicits these differentiating behaviors and judgements, the ramifications of perceived intergroup similarity for social interactions are relatively under-studied. Using a dyadic, multi-method approach, the current study examines the impact of intergroup similarity versus dissimilarity on physiology and behavior during interethnic interactions. Of key interest was a measure of physiological synchrony between partners, specifically covariation of the activity of their sympathetic nervous systems during the interaction. We also measured the impact of intergroup similarity on participant and partner affiliative behaviors during the interaction as well as participant and partner friendship initiation.

\section{Similarity in Social Versus Personal Identities}

Social identity is the part of a person's self-concept derived from group membership, together with the value and emotional significance attached to the group (Tajfel, 1978). People 
are motivated to achieve positive, meaningful social identities and people do so by emphasizing how their social groups differ from outgroups in positive ways. Belonging to groups that are distinct from other groups in positive ways can boost a person's self-esteem and solidify group bonds.

Social identity differs from personal identity, which is determined by the characteristics and drives of the individual person (Haslam, 2004; Tajfel, 1978). When individuals define themselves in terms of their personal identities, perceived similarity can draw individuals together (Berscheid, 1985; Festinger, 1954; Selfhout, Denissen, Branje, \& Meeus, 2009), even in intergroup contexts (Diehl, 1988, Study 1; Mallett, Wilson, \& Gilbert, 2008; Pinel \& Long, 2012; West, Magee, Gordon, \& Gullett, 2014). When social identity is salient, however, and relevant outgroups are too similar to the ingroup, then intergroup distinctiveness is undermined. In such situations, intergroup similarity makes it difficult to draw comparisons that favor the ingroup. Thus, social identity is threatened, and the need to differentiate intensifies (Brown, 1984; Jetten, Spears, \& Postmes, 2004; Tajfel, 1978) encouraging ingroup favoritism (Jetten, Spears, \& Manstead, 1996, Study 2; 1997, Study 2; 2001; Mummendey \& Schrieber, 1984; Roccas \& Schwarz, 1993), outgroup discrimination (Diehl, 1988, Study 2; Hornsey \& Hogg, 2000), and violence against the outgroup (Genthner, Shuntich, \& Bunting, 1975; Struch \& Schwarz, 1989).

Often, the most functional social identity is one in which people identify with both a subgroup, such as ethnicity, and a superordinate identity, such as nationality. Holding to dual identities preserves a sense of distinctiveness for members of all groups within the superordinate group while encouraging affiliation with outgroup members who ascribe to that broader social identity (Dovidio, Gaertner, \& Saguy, 2009). Even majority group members, who have the most 
to gain in maintaining a single national identity, benefit from ascribing to a dual identity during interactions with minority group members (Scheepers, Saguy, Dovidio, \& Gaertner, 2014). Although the current work does not attempt to manipulate a dual identity, it is presumed that by encouraging a sense of intergroup distinctiveness, a respect for mutual differences will pave the path toward interpersonal cohesion.

On the flip side, perceptions of intergroup dissimilarity can make people have anxiety about intergroup interactions and avoid them (Mallett et al., 2008). Intergroup differences fuel fears of rejection and embarrassment related to social and cultural misunderstandings (Stephan \& Stephan, 1985), and also encourage symbolic threat, the tendency to view an outgroup's cultural differences as threatening to the worldview of the ingroup (Stephan \& Stephan, 2000). Even holding to a dual identity can be disadvantageous for intergroup interactions, if subgroups within the superordinate group perceive themselves as more prototypical than other subgroups (Dovidio et al., 2009). Such perceptions encourage demonization of the other subgroups as inferior and deviant and promote bias and hostility against the outgroup.

So, it seems that both similarity or dissimilarity have the potential to negatively impact the quality of intergroup interactions. This past research might lead to the conclusion that social identities should be downplayed during intergroup interactions and personal identities should be emphasized. However, a large body of research shows that social identities must be salient during intergroup interactions in order for positive intergroup interactions to have an impact on intergroup attitudes (see Brown \& Hewstone, 2005, for a review). So, how do we best amplify the salience of social identities during intergroup interactions, by emphasizing similarity or dissimilarity between the social groups of interaction partners?

Based on the evidence reviewed, we anticipate that emphasizing social group 
distinctiveness, not similarity, during benign intergroup interactions would encourage a more positive interpersonal experience. While dissimilarity can give rise to anxiety during intergroup interactions, the anxiety-producing aspects of dissimilarity are less relevant in diverse contexts where intergroup contact is both frequent and benign. Indeed, after people experience a certain number of benign intergroup interactions they may cross a "contact threshold" wherein subsequent intergroup interactions reduce prejudice rather than increase anxiety (MacInnis \& Page-Gould, 2015). Thus, in keeping with the predictions of social identity theory, we anticipate that emphasizing intergroup dissimilarity will enhance intergroup interactions and we test this assumption in the context of an ethnically diverse university campus: The University of Toronto, Scarborough.

\section{Physiological Synchrony}

The current research tests how distinctiveness, or lack thereof, influences the interpersonal tenor of interethnic interactions at the physiological, behavioral, and subjective levels. In social interactions, the physiological activity of interaction partners can synchronize (e.g., Kaplan \& Bloom, 1960; Kraus \& Mendes, 2014; Levenson \& Gottman, 1983), a phenomenon called physiological synchrony. Physiological synchrony is striking because physiological states are relatively uncontrollable and are difficult for an interaction partner to perceive. Nonetheless, physiological synchrony has been observed within a variety social relationships, including between strangers (Henning, Boucsein, \& Gil, 2001; Henning \& Korbelak, 2005; Kaplan, Burch, Bloom, \& Edelberg, 1963), mothers and infants (Feldman, Magori-Cohen, Galili, Singer, \& Louzoun, 2011; Ham \& Tronick, 2009), romantic partners (Levenson \& Gottman, 1983; Reed, Randall, Post, \& Butler, 2013), and friends (Chanel, Kivikangas, \& Ravaja, 2012). Physiological synchrony also occurs during different forms of 
social contact, including cooperation (Strang, Funke, Russell, Dukes, \& Middendorf, 2014) and conflict (Levenson \& Gottman, 1983).

A naïve assumption to make about physiological synchrony is that it reflects a positive social experience. This assumption appears to only sometimes be true. Physiological synchrony is associated with both beneficial relational outcomes such as empathy (Marci \& Orr, 2006), enhanced group performance (Elkins, Muth, Hoover, Walker, Carpenter, \& Switzer, 2009), and increased social presence (Chanel et al., 2012), but also detrimental relational outcomes such as marital dissatisfaction (Levenson \& Gottman, 1983) and mutual dislike (Kaplan, Burch, \& Bloom, 1964). In order to disentangle the meaning of physiological synchrony, self-report and behavioral measures are critical to triangulating the interpersonal meaning of this internally shared state (Palumbo, et al., 2016). In the current study, we used behavioral and self-report measures of participant and partner affiliation and friendship initiation to complement our measure of physiological synchrony.

Physiological synchrony in the sympathetic nervous system. The sympathetic branch of the autonomic nervous system (SNS) enables a range of physiological responses for coping with environmental demands. When the SNS is activated, the heart contracts with greater speed, facilitating a greater exchange of oxygen and nutrients throughout the body (Berntson, Quigley, \& Lozano, 2007). The SNS is one of the two major stress axes in the body (the second being the hypothalamic-pituitary-adrenal axis; Blascovich \& Mendes, 2010). The SNS is typically associated with engagement in a task or situation (Blascovich, Mendes, Tomaka, Salomon, \& Seery, 2003; Seery, 2011). Covariation of the sympathetic nervous system was the first form of physiological synchrony observed in the lab (Kaplan \& Bloom, 1960), and it has been widely studied in the physiological synchrony literature (Levenson \& Gottman, 1983; Marci \& Orr, 
2006). Especially because SNS activation reflects engagement in a situation, sympathetic covariation during social interactions is thought to reflect a shared internal state (Levenson \& Gottman, 1983).

\section{Study Overview}

The main goal of this research was to examine how intergroup similarity influences interethnic interactions. Despite ample research showing the impact of intergroup distinctiveness on intergroup behavior and judgements (Jetten et al., 2004), this study is the first to examine the impact of intergroup distinctiveness on social interactions. We used an essay writing paradigm to manipulate perceived intergroup similarity and dissimilarity between East and South Asians before a social interaction that occurred in our laboratory at the University of Toronto, Scarborough. Thus, the social groups were salient in all interactions, but either the perceived similarities or dissimilarities between these groups were manipulated. ${ }^{1}$ East and South Asian cultures possess both similarities (e.g., traditional cultures, religious heritages) and differences (e.g., culinary traditions, phenotypic features), producing an ideal intergroup context in which to conduct our research. In addition, East and South Asians are about equally represented in the City of Toronto (Toronto City Planning, 2008), thus, we were able to study intergroup interactions from more than one group perspective without a relative minority/majority status difference between the social groups. The social interaction involved playing Hasbro's Jenga, a competitive party game that has been used to encourage positive interpersonal interactions in intergroup interaction research (Becker, Wright, Lubensky, \& Zhou, 2013; Page-Gould, Mendoz-Denton, \& Tropp, 2008; Wright, Aron, \& Tropp, 2002).

After the manipulation, participants interacted for 5 minutes while their sympathetic activity was continuously measured to capture physiological synchrony. We video-recorded the 
interactions for later observation to identify participants' and partners' affiliative behaviors. We also measured each participant's and partner's subjective initiation of friendship (i.e., selfreported friendship initiation) and behavioral friendship initiation (e.g., an opportunity to exchange email addresses). Given that perceived intergroup similarity encourages the desire to differentiate the ingroup from outgroups, we hypothesize that intergroup dissimilarity will promote affiliation and the initiation of friendship during intergroup interactions more than intergroup similarity. By observing processes across multiple levels (e.g., subjective, behavioral, physiological), we hoped to obtain a rich image of the functional importance of intergroup dissimilarity for intergroup interactions.

\section{Methods}

\section{Participants}

An equal number of East and South Asian Introductory Psychology students from the University of Toronto Scarborough, Canada $(N=106)$ participated in a 2-hour study in same-sex dyads. The sample was $51 \%$ female and the mean age was 20.15 years $\left(S D_{\text {age }}=1.96\right)$. We decided a priori to collect data until the end of the second semester of the academic year, provided that we had at least 50 dyads. We had to continue collecting data one month past the second semester to reach this goal. We compensated participants with two course credits, $\$ 20.00$, or a combination of credits and money in addition to a performance bonus.

\section{Procedure}

Participants were told that we were interested in "how people perceive and embody their social worlds." Participants completed an online survey prior to the experimental lab session. We did not analyze any pretest variables, but we provide a full list in the Supplemental Materials. After giving consent, participants orally answered questions pertaining to health and health 
behaviors and were then connected to the physiological equipment. Once we calibrated the physiological signals, participants sat alone for a five-minute baseline recording.

In a random order, participants then completed an essay that primed perceptions of similarity or dissimilarity between East Asians and South Asians on a computer. We then asked participants to smile for a photo, which we shared with their partner prior to the interaction. After seeing the photo of their partner, participants completed a brief pre-interaction questionnaire. We did not analyze any data from these lab surveys, but we list the measures included in them in the Supplemental Materials. Participants were then disconnected from the physiological equipment by removing the leads from the recording machines (i.e., all electrodes remained attached to participants during the move). Participants were moved to a room equipped for dyadic psychophysiological recordings for the social interaction task, and their leads were connected to the dyadic recording machines.

The social interaction task consisted of participants playing a party game, Hasbro’s Jenga, for small cash rewards for a duration of five minutes. Over this period, participants' physiological responses were continuously recorded and time-synced with one another by sending the signals through the same analog-to-digital converter. The interaction was also videotaped using two separate cameras, with each camera facing an individual participant.

After the social interaction, participants were disconnected from the dyadic recording devices and returned to their separate rooms. They sat for a 5-minute physiological recovery period during which they completed post-interaction questionnaires while their physiological responses were recorded (a full list of questionnaires, including measures unreported here, can be found in Supplemental Materials). Participants were then debriefed and compensated for their time. 


\section{Materials}

Similarity prime. Participants wrote an essay to manipulate perceptions of intergroup similarity or dissimilarity. To vary perceptions of intergroup similarity versus intergroup dissimilarity, participants were randomly assigned to write an essay with one of the following prompts: "Please write a short essay describing the ways that East Asians and South Asians are SIMILAR to each other." or "Please write a short essay describing the ways that East Asians and South Asians are DISSIMILAR to each other." Participants were instructed to spend up to five minutes writing each essay and to write between two and five paragraphs in length. In total, the similarity/dissimilarity essays contained an average of 107.75 words per essay $(S D=49.92)$, and whether participants wrote about similarity or dissimilarity was unrelated to word count, $F(1$, $103)=.002, p=.965 .^{2}$ Randomization of the experimental primes meant that members of the same dyad did not always receive the same pair of experimental primes. By randomizing the primes for each participant (i.e., instead of at the level of the dyad), our level of analysis is the level of the individual. In the supplement, we report the results with covariates for the partners' primes included.

Physiological data. We measured sympathetic nervous system activity through PreEjection Period (PEP). PEP is the time between when the ventricles contract to when the left ventricular valve opens to eject blood from the heart, measured in milliseconds. PEP is a pure index of SNS activation (Mendes, 2009). Shorter intervals reflect greater SNS activation. Physiological synchrony of the SNS can thus be observed through the covariation of PEP measured from two people over time.

Ventricular contraction is measured with electrocardiography (ECG) and the opening of the left ventricular valve is derived from impedance cardiography (ICG). ${ }^{3}$ ECG was recorded 
with electrodes in modified Lead II placement and sent to a computer through a Biopac ECG100C Module and MP150 amplifier (Biopac Systems, Inc., Goleta, California). ICG was recorded using four band electrodes placed around the neck and thorax (Sherwood et al., 1990) and sent to the computer through a 4000 Hutcheson Impedance Cardiograph (Bio-Impedance Technology Inc., Chapel Hill) connected to the Biopac MP150 system. After placing the impedance bands, experimenters measured the distance in $\mathrm{cm}$ between the inner edges of the band electrodes in the front and the back. Data was acquired and monitored in real time using AcqKnowledge data acquisition software (Biopac Systems, Inc., Goleta, California) at a sampling rate of $1000 \mathrm{~Hz}$.

ECG and ICG recordings were scored with ANSLAB Professional version 2.51 (University of Basel; Wilhelm, Grossman, \& Roth, 1999). The lead author visually inspected each ECG file to ensure that each heart beat (R-wave), which represents the depolarization of the ventricles in the QRS waveform, was correctly identified. The impedance signals were then averaged into 1-minute epochs with reference to the R-wave of the scored ECG waveforms (Lozano et al., 2007; Riese et al., 2003). The lead author examined this averaged data to identify the onset of ventricle depolarization (Q-point) and the opening (B-point) and closing (X-point) of the left ventricular valve, keeping within the constraints of physiological plausibility (Blascovich, Mendes, Vanman, \& Dickerson, 2011). The average time between the onset of the depolarization of the ventricles (Q-point) and the opening of the left ventricular valve (B-point) each minute served as our derivation of PEP and thus our measure of sympathetic activity in each minute. Smaller PEP values (i.e., shorter PEP intervals) reflect increased sympathetic activity. 
We also measured pulse photoplethysmograph (PPG) and skin temperature on separate fingers, and electrodermal activity (EDA) in the palm of the hand. Moreover, from our ICG recording, respiration rate, stroke volume, and cardiac output can be determined. Skin temperature, EDA, and respiration rate data were not processed at the time of writing.

Physiological synchrony. To account for individual differences in sympathetic activity and to be consistent with the physiological synchrony literature, sympathetic reactivity was calculated by subtracting PEP during the last minute of baseline from PEP during each minute of the social interaction (Waters, West, \& Mendes, 2014). We used a multilevel model to first check for possible differences in baseline PEP across conditions. To do this, baseline PEP was regressed on the similarity prime with a random intercept for dyad. This test revealed no significant differences in baseline values between participants assigned to the similarity or dissimilarity primes, $b=-0.23,95 \% \mathrm{CI}[-2.36,1.90], S E=1.06, t(52)=-0.22, p=.828, r=$ -.03. The covariation between participant sympathetic reactivity and partner sympathetic reactivity over the 5 minutes of the social interaction was our measure of physiological synchrony.

\section{Dependent variables.}

Affiliative behavior. Blind to condition, ten independent raters viewed videos of the interactions and coded for participant and partner's affiliative behaviors and friendship initiation using Noldus Observer XT 11.0 software (Noldus Information Technology, 2012). Raters coded files assigned to them at random. A subset of the coded files $(n=50)$ were randomly assigned to the raters so that inter-rater reliability could be assessed and no file was coded by more than two independent raters. Different independent raters worked on the project over the course of the coding period, such that all raters did not rate all files. The number of files coded per rater ranged 
from one to twenty-four files. Only one independent rater rated a single file. Interrater reliability, as reported below, was calculated for each independent rating using the intra-class correlation coefficient $(I C C)$. The $I C C$ is the appropriate measure of reliability when raters are not constant across files. Note that $I C C$ has different interpretation ranges relative to other reliability measures like Cronbach's alpha: "poor" $<.4 \leq$ "fair" $<.6 \leq$ "good" $<.75 \leq$ "excellent" (Fleiss 1981; Shrout \& Fleiss, 1979). We collected additional self-reported and behavioral measures of friendship initiation, as well.

Participant and partner affiliative behavior was measured with positive affect, smiling, laughing, and sociability obtained from the videos. For positive affect, raters marked the start and end points for any expressions of verbal or non-verbal enjoyment for each participant and partner. Inter-rater reliability for positive affect duration was excellent $I C C=.76,(M=0.20, S D$ $=0.33$ ). Raters also indicated the frequency with which participants and partners smiled and laughed on the following two items, "How frequently did the participant express positive emotions: smiling?...laughing?” Observers indicated the frequency of each behavior on a scale from 1 (never) to 7 (extremely frequently). Inter-rater reliability for laughing was fair, $I C C_{\text {laugh }}$ $=.59, M=4.33, S D=1.52$, and inter-rater reliability for smiling was good, $I C C_{\text {smile }}=.60, M=$ 4.79, $S D=1.42$. Finally, raters indicated how sociable each participant and partner acted using the following six items, "How socially skilled do you think the participant was at...”: “... making a good first impression”, “...minimizing social awkwardness”, “...being at ease”, “...making his/her partner feel at ease", “...taking time to listen to her/his partner and showing interest in what they have to say", and “...being interesting to her/his partner." Items were rated on a scale from 1 (not resourceful at all) to 7 (highly resourceful). The inter-rater reliability for this 
measure was fair, $I C C=.48$, and the scale internal consistency was excellent $(\alpha=.98, M=4.53$, $S D=1.27)$

Friendship initiation. We used a combination of behavioral and self-report measures to determine whether participants and their partners wanted to initiate friendship. Raters rated participant and partner's apparent friendship initiation using the following four items, "How much do you think the participant liked his/her partner?", "How likely is it that the two partners would become friends?", "How much do you think this participant would want to interact with his/her partner in the future?", and "How much do you think this participant enjoyed interacting with his/her partner?" Items were rated on a scale from 1 (not at all) to 7 (very). The inter-rater reliability for this measure was fair, $I C C=.46$, and the scale internal consistency was excellent $(\alpha=.97, M=4.62, S D=1.17)$.

Each participant and partner also self-reported their interest in initiating friendship using modified versions of the four items used by the independent observers (e.g., "How much do you like your partner?") $)^{4}$. The scale had excellent internal reliability $(\alpha=.90, M=5.31, S D=0.93)$. Finally, we collected a behavioral measure of friendship initiation by giving each participant and partner the opportunity to exchange their email addresses. Specifically, each participant and partner were told, "If you enjoyed your interaction and would be willing to see this person in the future, then please enter your email address below. We will only exchange your contact information if both you and your partner agree to exchange this information." Most participants said they would share their email with their partner $(66.98 \%)$.

\section{Results}

We inspected all measures for the presence of extreme outliers by examining boxplots (Figure S1). The PEP reactivity values, positive affect duration, and observed and self-reported 
friendship initiation for participants and partners all had extreme outliers. We winsorized these outliers by replacing low outliers with the $5^{\text {th }}$ percentile score and high outliers with the $95^{\text {th }}$ percentile score. We then reinspected boxplots of the measures that previously had outliers (Figure S2) and confirmed that all of our measures no longer had extreme outliers.

\section{Physiological Synchrony}

The relationship between participant sympathetic reactivity (i.e., changes in PEP from baseline to the interaction task) and partner sympathetic reactivity was our measure of physiological synchrony. Partner sympathetic reactivity was modeled as a function of participant sympathetic reactivity and similarity prime $($ similarity $=1$, dissimilarity $=-1)$ in a 3-level multilevel model ${ }^{5}$ where sympathetic reactivity at each of 5 minutes was nested within participants and participants were nested within dyads. We modeled random intercepts for both the participant and dyad and a random slope for participant sympathetic reactivity at the level of the dyad, using the nlme package (Pinheiro, Bates, DebRoy, Sarkar, \& R Core Team, 2015) for the statistical package R (R Core Team, 2014). ${ }^{6}$ This multilevel model was estimated with an unstructured covariance matrix and degrees of freedom were estimated using the between-within method. Partial effect sizes are provided as correlation coefficients, converted from the $t$-statistic and degrees of freedom associated with each slope (Kashdan \& Steger, 2006). See the Supplemental Materials for the multilevel equations that correspond to this model.

The full model results are presented in Table 1. Neither the main effects of similarity prime, $b=0.45,95 \% C I[-1.60,2.50], S E=1.02, t(49)=0.45, p=.658$, nor participant sympathetic reactivity, $b=0.08,95 \% C I[-0.05,0.20], S E=0.06, t(332)=1.17, p=.243$, predicted partner sympathetic reactivity. ${ }^{7}$ However, the similarity prime and participant 
sympathetic reactivity interacted to predict partner sympathetic reactivity, $b=-0.15,95 \%$

$$
C I[-0.26,-0.04], S E=0.06, t(332)=-2.60, p=.010 .
$$

Simple effects were examined at each level of the experimental prime (Aiken \& West, 1991). Analyses revealed evidence of physiological synchrony among dyads in which the participant had been primed with intergroup dissimilarity, $b=0.22,95 \% C I[0.06,0.39], S E=$ $0.08, t(332)=2.68, p=.008$, but not among dyads in which the participant had been primed with intergroup similarity, $b=-0.07,95 \% C I[-0.25,0.10], S E=0.09, t(332)=-0.83, p=.406$. Thus, perceived intergroup dissimilarity encourages mutual patterns of sympathetic reactivity during intergroup interactions, whereas perceived intergroup similarity does not. In keeping with our rationale, much of this effect occurs specifically when sympathetic reactivity increases (i.e., lower PEP values; Figure 1).

\section{Affiliative Behaviors and Friendship Initiation}

We measured multiple behaviors and self-reports reflecting participant and partner affiliative behaviors and the initiation of friendship, so we took all of our dependent variables into account while also minimizing the number of statistical tests that we ran with these variables. Thus, we used the multiple measures as indicator variables of two latent variables: participant and partner affiliative behavior (i.e., general positive affect, smiling, laughing, sociability) as well as participant and partner friendship initiation (i.e., coder-rated friendship initiation, self-rated friendship initiation, email exchange) using multilevel structural equation modeling (MSEM). We used the lavaan (Rosseel, 2012) and lavaan.survey (Oberski, 2014) packages in $\mathrm{R}$ to conduct the analysis with participants nested in dyads and the semPlot package (Epskamp, 2014) to create figures from our models. A correlation matrix of all variables 
included in this analysis is provided in Table 2 with the means and standard deviations for each variable at the bottom.

We originally hypothesized that the primes would affect participant and partner affiliative behaviors during the interaction, and both participant and partner affiliative behaviors during the interaction would in turn predict participant and partner friendship initiation. However, this model did not have acceptable model fit, $S R M R=.15, R M S E A=.21,90 \%$ CI $[.19, .24], C F I$ $=.54$ (see Figure S6 in Supplemental Materials). As can be seen in the correlation matrix (Table 2), the similarity primes were systematically less related to participant affiliative behaviors than partner affiliative behaviors. So, we trimmed the initial model to only include partner affiliative behaviors.

The final model is shown in Figure 2. This model fit the data acceptably well, SRMR $=.07, \mathrm{RMSEA}=.10,90 \% \mathrm{CI}[.06, .15], C F I=.94$. Partners exhibited more affiliative behaviors toward participants who had been primed with dissimilarity, $b=-7.18,95 \%$ CI $[-12.49,-1.86]$, $S E=2.71, Z=-2.65, p=.008$. Participants initiated friendship in partners who showed more affiliative behaviors towards them, $b=0.02,95 \%$ CI $[0.01,0.04], S E=0.01, Z=3.77, p<.001$. Moreover, there was a reliable indirect effect such that the dissimilarity prime predicted participant friendship initiation through partner affiliative behavior, $b=-0.16,95 \% \mathrm{CI}[-0.32$, $-0.01], S E=0.08, Z=-2.02, p=.043$.

\section{Physiological Synchrony, Affiliative Behaviors, and Friendship Initiation}

Finally, we examined the relationship between our measure of physiological synchrony and the measures included in the latent variables, participant and partner affiliative behavior and friendship initiation. We ran a model predicting partner SNS reactivity from participant SNS reactivity, and we extracted the coefficients for the random slopes of participant SNS. This slope 
is an unstandardized estimate of SNS covariance. We then correlated these slopes with each measure that we had included in our affiliative behavior and friendship initiation constructs for each participant and partner. As shown in the correlation matrix (Table 2), for both participants and partners, physiological synchrony predicted positive affect duration, $r=0.31, t(87)=3.08, p$ $=.003$, and social competence, $r=0.21, t(98)=2.14, p=.035$. Physiological synchrony trended toward positive relationships with laugh $(r=0.19, t(98)=1.91, p=.059)$ and smile frequency $(r$ $=0.19, t(91)=1.80, p=.075)$, but these effects were not reliable. These correlations affirm that, in the context of a friendly interethnic interaction, synchrony between cross-ethnic partners' SNS reactivity can reflect a mutually positive social experience.

\section{Discussion}

Using a multimethod approach, we demonstrated that intergroup dissimilarity, not similarity, predicts physiological synchrony, elicits affiliative behaviors in outgroup interaction partners, and indirectly facilitates friendship initiation. Although prior research shows the deleterious effects of intergroup similarity on people's attitudes, judgments, and behaviors toward outgroups (Jetten et al., 2004), no prior research has examined the impact of intergroup similarity on intergroup interactions until now. Indeed, the current work uniquely supports the social identity perspective by showing that intergroup dissimilarity, emphasized before an interethnic interaction, produces a more positive social experience than does emphasizing similarity. By illustrating the counterintuitive value of emphasizing group differences during interethnic interactions, our research demonstrates that the social identity perspective is functionally relevant for ensuring the positive tenor of interpersonal relationships and possibly even for the development of cross-group friendships. 
Intergroup dissimilarity indirectly predicted participant friendship initiation through the affiliative behavior of the partner. We interpret this indirect effect from a dyadic perspective: participants primed with intergroup dissimilarity elicited more affiliative behavior from their partner, and in turn, participants responded positively to their partners signals of desire for affiliation by initiating friendship. This successful exchange is particularly promising given that people commonly miscommunicate friendship intentions in intergroup contexts (Vorauer, 2005). People have a tendency to erroneously assume that they have conveyed interest in friendship with outgroup members when they have not objectively done so, a phenomenon called signalamplification bias (Vorauer, 2006; Vorauer \& Sakamoto, 2006). This bias is driven by the perception that one is seen by other people as one sees oneself (Kenny \& DePaulo, 1993), a process that perceived similarity could exaggerate (Vorauer \& Cameron, 2002). Perhaps participants primed with dissimilarity prior to an intergroup interaction do not assume that their partners innately understand them, thus potentially reducing the signal-amplification bias.

It remains unclear why intergroup dissimilarity only influenced the affiliative behavior of partners. We generally assume that people behaved positively across conditions but that something in the participants' behaviors elicited affiliative behaviors in their partner. We can think of at least two possible explanations, neither of which we can measure in the present study but hopefully can be considered in future research.

First, intergroup dissimilarity might have predicted greater affiliation among partners, but not participants, because the positive affect and subtle non-verbal behavior of people primed with dissimilarity was more genuine than that of people primed with similarity. Accordingly, people primed with dissimilarity might have been more likely to evoke positive affect from their partners than people primed with similarity. Yet with the current measures, we cannot 
distinguish the genuineness of participants' behaviors and affect. The angle of our camera and the low resolution of the video image prevented us from coding specific facial muscles that would have allowed us to code for the presence of real and fake smiles. Moreover, we did not ask participants to report how genuinely they felt positive affect. However, we think it is possible that partners were responding positively to participants primed with dissimilarity because those participants were more genuinely enjoying the interaction.

Another possibility is that the intergroup dissimilarity prime elicited guilt in participants. Given that people are motived to emphasize how their social groups differ from outgroups in positive ways, it seems plausible that participants might have emphasized their group's specific privileges, relative to the outgroup of their partners. In turn, participants may have behaved in ways that were reconciliatory and deferent, lowering their partners' guard and encouraging the affiliative behavior we observed. Unfortunately, we did not code for signs of guilt or deferent behaviors in our data. To address both questions, future research should make sure to use video cameras with sufficient resolution and the proper angle to code specific facial muscles known to be associated with emotion displays.

Demonstrating that cultural distinctiveness improves the tenor of interethnic interactions, our work suggests important implications for policies of multiculturalism. Multiculturalism reflects the efforts of governments and societies to ensure that newcomers maintain a sense of cultural distinctiveness while developing the cultural fluency required to function within the receiving society (Reitz, 2009). Relative to policies of assimilation, which require newcomers to eschew their cultural identity in favor of the dominant culture, our work supports policies of multiculturalism for increasing harmony within diverse societies. In recent times, multicultural values have given way to populist fears about the perceived threat immigrants pose to receiving 
societies (Alvares \& Dahlgren, 2016; Hughey, 2014). Indeed, politicians have emphasized group differences in their efforts to drum up support for legislation that marginalizes immigrants (Green, 2016; Kteily \& Bruneau, 2017). Thus, it seems plausible that when authorities do not support policies of multiculturalism, emphasizing group differences may have a chilling effect on intergroup relationships. We caution that emphasizing group differences in supportive environments might be critical to the success of such interventions.

The current study is unique among the physiological synchrony literature because it is the first to show evidence of physiological synchrony during an intergroup interaction. As reviewed in the introduction, physiological synchrony occurs during both "positive" and "negative" social interactions, so it must be interpreted in the context of other measures. In addition to eliciting physiological synchrony, intergroup dissimilarity enhanced the interpersonal dynamics between outgroup strangers. While participants' interactions were positive overall (e.g., $67 \%$ of participants gave their email address to their partner), the dissimilarity prime nonetheless predicted more affiliative behavior from outgroup partners and more friendship initiation by participants downstream.

Additionally, our measure of physiological synchrony predicted the duration of positive affect expressed by both participants and partners as well as independent ratings of participant's and partner's social competence. Together, these findings suggest that physiological synchrony in intergroup interactions can be associated with positive interpersonal processes. This finding suggests that some aspects of prejudice reduction interventions could be geared toward increasing physiological synchrony, which may enable these interventions to reach people resistant to more explicit prejudice reduction techniques. 
Eliciting physiological synchrony by manipulating how people process and apply information about themselves and others is another way that the current study extends prior physiological synchrony research. Few studies have attempted to induce physiological synchrony by changing how people see themselves relative to others (for an exception, see Kraus \& Mendes, 2014). Most studies examine the emergence of physiological synchrony as a function of relationship type (e.g., parent-child synchrony as a function of relationship quality; Baker, et al., 2015), social experience (e.g., synchrony between audience and performers at a dance recital; Bachrach, Fontbonne, Joufflineau, \& Ulloa, 2015), or some combination of relationship type and social experience (e.g., mother-infant synchrony after exposing mother to a stressor; Waters, et al., 2014). Our study is the first to demonstrate that manipulating perceptions of social identity can increase physiological synchrony between relative strangers. Thus, our study paves the way for future work to demonstrate physiological synchrony via manipulation of people's social cognitions.

\section{Limitations and Future Directions}

A key limitation in the current research is the lack of a no-prime control condition. Without a control condition, it is difficult to assess whether intergroup similarity or dissimilarity plays the more important role influencing our outcome measures. It is possible that intergroup dissimilarity primes made people more at ease with their partner because their sense of distinctiveness was not threatened. Alternatively, similarity primes might have made people feel ill-at-ease with their partner because their sense of distinctiveness was threatened. Of course, both primes could have moved people in opposite directions. Finally, the lack of a control condition prevents us from knowing whether the amount of physiological synchrony present in 
the dissimilarity condition is more than, less than, or the same as the amount of physiological synchrony experienced under neutral circumstances.

The current study was also limited in the size of its sample (i.e., 106 participants in 53 dyads). Time constraints prevented us from pursuing data collection beyond 50 dyads. Yet, most of the models tested were a 2-cell design (similarity versus dissimilarity). Thus, there were a little over 50 participants per cell. Moreover, the model predicting sympathetic covariation was a mixed-design, which amplified statistical power. Nevertheless, we encourage a degree of caution in generalizing the findings from this study until our results are replicated with larger samples.

Another limitation relates to our decision to operationalize physiological synchrony as the covariation of five 1-minute segments of aggregated physiological signals across the social interaction. By aggregating these continuous physiological signals, we necessarily averaged out other interesting patterns of information that might have been occurring between partners within a smaller time frame. Some dyads' sympathetic responses were in sync, according to the aggregate signals, however, other physiological patterns and relationships might have been present in the data (but see the Supplemental Materials for models examining physiological synchrony of the parasympathetic nervous system and patterns of physiological challenge or threat). Examining physiological synchrony with higher time resolution would enable us to see relationships that cannot be seen when aggregating over a larger time period (e.g., Müller \& Lindenberger, 2011; Waters et al., 2014).

From evidence presented in the current study, we see some promising lines of inquiry for future research. A particularly important extension of this study will be to gauge whether simultaneously manipulating similarity of personal identity and dissimilarity of social identity can provide the most optimal conditions for the emergence of cross-group friendships. We 
predict that manipulations that simultaneously emphasize interpersonal similarity and intergroup dissimilarity will provide an optimal balance of distinctiveness and belonging and, thus, be a particularly potent way to encourage cross-group friendships. Likewise, we expect that simultaneously manipulating perceptions of interpersonal dissimilarity and intergroup similarity will undermine one's sense of belonging and distinctiveness and, thus, be particularly corrosive for intergroup interactions.

Future research should also identify the precise mechanisms through which intergroup dissimilarity encourages affiliative behaviors and friendship initiation. We based our hypotheses on social identity and optimal distinctiveness theories, and thus we assume that intergroup similarity undermines people's sense of positive distinctiveness, leading people to distance themselves from their partner. An alternate or additional mechanism could be that dissimilarity provides opportunities for self-expansion, for which many people are motivated (Aron \& Aron, 1997). Self-expansion theory shows that the merging of individuals' identities, resources, and perspectives is a key element in successful social bonding. Altogether, many pathways likely exist between intergroup dissimilarity, physiological synchrony, and positive interpersonal behaviors.

\section{Conclusion}

People are drawn toward others with whom they share personal similarities. The current study suggests that highlighting a person's social dissimilarity can also play an important role in the early formation of friendships. This research supports social policies of multiculturalism, which encourages the maintenance of subcultural identities within diverse societies, as opposed to cultural assimilation, which encourages members of a society to adopt a homogenous culture. While not all social contexts might support such a framework, a large body of research on social 
identity theory suggests there is a social utility in highlighting group differences during relatively pleasant intergroup interactions. Our work provides evidence that embracing group differences can encourage friendship in diverse societies. 


\section{References}

Aiken, L. S., \& West, S. G. (1991). Multiple regression: Testing and interpreting interactions. Thousand Oaks: Sage Publishing.

Alvares, C., \& Dahlgren, P. (2016). Populism, extremism and media: Mapping an uncertain terrain. European Journal of Communication, 31, 46-57.

Aron, A., \& Aron, E. N. (1997). Self-expansion motivation and including other in the self. In S. Duck (Ed.), Handbook of Personal Relationships: Theory, Research and Interventions (pp. 251-270, 2nd Ed). Hoboken, NJ, US: John Wiley \& Sons Inc.

Bachrach, A., Fontbonne, Y., Joufflineau, C., \& Ulloa, J. L. (2015). Audience entrainment during live contemporary dance performance: Physiological and cognitive measures. Frontiers in Human Neuroscience, 9, Article 179.

Baker, J. K., Fenning, R. M., Howland, M. A., Baucom, B. R., Moffitt, J., \& Erath, S. A. (2015). Brief report: A pilot study of parent-child biobehavioral synchrony in autism spectrum disorder. Journal of Autism and Developmental Disorders, 45, 4140-4146.

Becker, J. C., Wright, S. C., Lubensky, M. E., \& Zhou, S. (2013). Friend or ally: whether crossgroup contact undermines collective action depends on what advantaged group members say (or don’t say). Personality and Social Psychology Bulletin, 39, 442-455.

Berntson, G. G., Quigley, K. S., \& Lozano, D. (2007). Cardiovascular psychophysiology. In J. T. Cacioppo, L. G. Tassinary, \& G. G. Berntson (Eds.), Handbook of psychophysiology, (3rd ed., pp. 182-210). Cambridge: Cambridge University Press.

Berscheid, E. (1985). Interpersonal attraction. In G. Lindzey \& E. Aronson (Eds.), Handbook of 
social psychology: Vol. 2. Special fields and application (3rd ed., pp. 413-485). New York: Random House.

Blascovich, J., \& Mendes, W. B. (2010). Social psychophysiology and embodiment. In S. Fiske \& D. T. Gilbert (Eds.), The Handbook of Social Psychology (5 ${ }^{\text {th }}$ ed., pp. 194-227). New York: Wiley.

Blascovich, J., Mendes, W. B., Vanman, E., \& Dickerson, S. (2011). Social psychophysiology for social and personality psychology. London: Sage Publications Ltd.

Blascovich, J., Mendes, W. B., Tomaka, J., Salomon, K., \& Seery, M. (2003). The robust nature of the biopsychosocial model challenge and threat: A reply to Wright and Kirby. Personality and Social Psychology Review, 7, 234-243.

Brewer, M. B. (1991). The social self: On being the same and different at the same time. Personality and Social Psychology Bulletin, 17, 475-482.

Brown, R. (1984). The role of similarity in intergroup relations. In H. Tajfel (Ed.), The social dimension: European developments in social psychology. Cambridge: Cambridge University Press.

Brown, R., \& Hewstone, M. (2005). An integrative theory of intergroup contact. Advances in Experimental Social Psychology, 37, 255-343.

Chanel, G., Kivikangas, J. M., \& Ravaja, N. (2012). Physiological compliance for social gaming analysis: Cooperative versus competitive play. Interacting with Computers, 24, 306316.

City of Toronto, City Planning Division. (2008). Backgrounder: Release of the 2006 Census on Ethnic Origin and Visible Minorities. Retrieved from 
https://www1.toronto.ca/city_of_toronto/social_development_finance_administration/f iles/pdf/2006_ethnic_origin_visible_minorities_backgrounder.pdf

Diehl, M. (1988). Social identity and minimal groups: The effects of interpersonal and intergroup attitudinal similarity on intergroup discrimination. British Journal of Social Psychology, $27,289-300$.

Dovidio, J. F., Gaertner, S. L., \& Saguy, T. (2009). Commonality and the complexity of "we": Social attitudes and social change. Personality and Social Psychology Review, 13, 3-20.

Elkins, A. N., Muth, E. R., Hoover, A. W., Walker, A. D., Carpenter, T. L., \& Switzer, F. S. (2009). Physiological compliance and team performance. Applied Ergonomics, 40, $997-$ 1003.

Epskamp, S. (2014). semPlot: Path diagrams and visual analysis of various SEM packages' output. $R$ package version 1.0.1. https://CRAN.R-project.org/package=semPlot

Feldman, R., Magori-Cohen, R., Galili, G., Singer, M., \& Louzoun, Y. (2011). Mother and infant coordinate heart rhythms through episodes of interaction synchrony. Infant Behavior \& Development, 34, 569-577.

Festinger, L. (1954). A theory of social comparison processes. Human Relations, 7, 117-140.

Fleiss, J. L. (1981). Balanced incomplete block designs for inter-rater reliability studies. Applied Psychological Measurement, 5, 105-112.

Genthner, R., Shuntick, R., \& Bunting, K. (1975). Racial prejudice, belief similarity, and human aggression. Journal of Psychology, 91, 229-234.

Green, D. (2016). The Trump hypothesis: Testing immigrant populations as a determinant of 
violent and drug-related crime in the United States. Social Science Quarterly, 97, 506524.

Ham, J., \& Tronick, E. (2009). Relational psychophysiology: Lessons from mother-infant physiology research on dyadically expanded states of consciousness. Psychotherapy Research, 19, 619-632.

Haslam, S. A. (2004). Psychology in organizations. London: Sage Publishing.

Henning, R. A., Boucsein, W., \& Gil, M. C. (2001). Social-physiological compliance as a determinant of team performance. International Journal of Psychophysiology, 40, 221232.

Henning, R. A., \& Korbelak, K. T. (2005). Social-psychophysiological compliance as a predictor of future team performance. Psychologia: An International Journal of Psychology in the Orient, 48, 84-92.

Hornsey, M. J., \& Hogg, M. A. (2000). Subgroup relations: A comparison of mutual intergroup differentiation and common ingroup identity models of prejudice reduction. Personality and Social Psychology Bulletin, 26, 242-256.

Hughey, M. W. (2014). White backlash in the 'post-racial' United States. Ethnic and Racial Studies, 37, 721-730.

Jetten, J., Spears, R., \& Postmes, T. (2004). Intergroup distinctiveness and differentiation: a meta-analytic integration. Journal of Personality and Social Psychology, 86, 862-879.

Jetten, J., Spears, R., \& Manstead, A. S. R. (1996). Intergroup norms and intergroup discrimination: Distinctive self-categorization and social identity effects. Journal of Personality and Social Psychology, 71, 1222-1233. 
Jetten, J., Spears, R., \& Manstead, A. S. R. (1997). Distinctiveness threat and prototypicality: Combined effects on intergroup discrimination and collective self-esteem. European Journal of Social Psychology, 27, 635-657.

Jetten, J., Spears, R., \& Manstead, A. S. R. (2001). Similarity as a source of differentiation: The role of group identification. European Journal of Social Psychology, 31, 621-640.

Kaplan, H. B., \& Bloom, S. W. (1960). The use of sociological and social-psychological concepts in physiological research: A review of selected experimental studies. Journal of Nervous and Mental Disease, 131, 128-134.

Kaplan, H.B., Burch, N.R., \& Bloom, S.W. (1964). Physiological covariation and sociometric relationships in small peer groups. In P. H. Liederman and D. Shapiro (Eds.), Psychobiological approaches to social behavior (pp. 92-109). Stanford: Stanford University Press.

Kaplan, H. B., Burch, N. R., Bloom, S. W., \& Edelberg, R. (1963). Affective orientation and physiological activity (GSR) in small peer groups. Psychosomatic Medicine, 25, 245 252.

Kashdan, T. B., \& Steger, M. F. (2006). Expanding the topography of social anxiety an experience-sampling assessment of positive emotions, positive events, and emotion suppression. Psychological Science, 17, 120-128.

Kenny, D. A., \& DePaulo, B. M. (1993). Do people know how others view them? An empirical and theoretical account. Psychological Bulletin, 114, 145-161.

Kraus, M. W., \& Mendes, W. B. (2014). Sartorial symbols of social class elicit class-consistent behavioral and physiological responses: A dyadic approach. Journal of Experimental 
Psychology: General, 143, 2330-2340.

Kteily, N., \& Bruneau, E. (2017). Backlash: The politics and real-world consequences of minority group dehumanization. Personality and Social Psychology Bulletin, 43, 87104.

Leonardelli, G.J., Pickett, C.L., \& Brewer, M.B. (2010). Optimal distinctiveness theory: A framework for social identity, social cognition and intergroup relations. In M. Zanna \& J. Olson (Eds.) Advances in Experimental Social Psychology (Vol. 43, pp. 65-115). New York, NY, US: Elsevier.

Levenson, R. W., \& Gottman, J. M. (1983). Physiological and affective predictors of change in relationship satisfaction. Journal of Personality and Social Psychology, 49, 85-94.

Lozano, D. L., Norman, G., Knox, D., Wood, B. L., Miller, B. D., Emery, C. F., \& Berntson, G. G. (2007). Where to B in dZ/dt. Psychophysiology, 44, 113-119.

MacInnis, C. C., \& Page-Gould, E. (2015). How can intergroup interaction be bad if intergroup contact is good? Exploring and reconciling an apparent paradox in the science of intergroup relations. Perspectives on Psychological Science, 10, 307-327.

Mallett, R. K., Wilson, T. D., \& Gilbert, D. T. (2008). Expect the unexpected: Failure to anticipate similarities leads to an intergroup forecasting error. Journal of Personality and Social Psychology, 94, 265-277.

Marci, C. D., \& Orr, S. P. (2006). The effect of emotional distance on psychophysiologic concordance and perceived empathy between patient and interviewer. Applied Psychophysiology and Biofeedback, 31, 115-128.

Mendes, W. B. (2009). Assessing autonomic nervous system activity. In E. Harmon-Jones and J. 
Beer (Eds.), Methods in Social Neuroscience. New York: Guilford Press.

Müller, V., \& Lindenberger, U. (2011). Cardiac and respiratory patterns synchronize between persons during choir singing. PloS One, 6, e24893.

Mummendey, A., \& Schrieber, H. D. (1984). Social comparison, similarity and ingroup favouritism. European Journal of Social Psychology, 14, 231-233.

Oberski, D. L. (2014). lavaan.survey: an R package for complex survey analysis of structural equation models. Journal of Statistical Software, 57, 1-27.

Page-Gould, E., Mendoza-Denton, R., \& Tropp, L. R. (2008). With a little help from my crossgroup friend: Reducing anxiety in intergroup contexts through cross-group friendship. Journal of Personality and Social Psychology, 95, 1080-1094.

Palumbo, R.V., Marraccini, M. E., Weyandt, L. L., McGee, H., Wilder-Smith, O., Goodwin, M. S. (2016). Interpersonal Physiological Research: A systematic review of the literature. Personality and Social Psychology Review, 1-43.

Pinel, E. C., \& Long, A. E. (2012). When I's meet: Sharing subjective experience with someone from the outgroup. Personality and Social Psychology Bulletin, 38, 296-307.

Pinheiro J., Bates D., DebRoy S., Sarkar D., \& R Core Team (2015). nlme: Linear and Nonlinear Mixed Effects Models. R package version 3.1-122. http://CRAN.Rproject.org/package $=$ nlme.

R Core Team (2014). R: A language and environment for statistical computing. R Foundation for Statistical Computing, Vienna, Austria. URL http://www.R-project.org/.

Raudenbush, S. W. (1997). Statistical analysis and optimal design for cluster randomized trials. Psychological Methods, 2(2), 173. 
Reed, R. G., Randall, A. K., Post, J. H., \& Butler, E. A. (2013). Partner influence and in-phase versus anti-phase physiological linkage in romantic couples. International Journal of Psychophysiology, 88, 309-316.

Riese, H., Groot, P. F., van den Berg, M., Kupper, N. H., Magnee, E. H., Rohaan, E. J., ... \& de Geus, E. J. (2003). Large-scale ensemble averaging of ambulatory impedance cardiograms. Behavior Research Methods, Instruments, \& Computers, 35, 467-477.

Reitz, J. G. (2009). Assessing multiculturalism as a behavioural theory. In J. G., Reitz, R. Breton, K. K. Dion, \& K. L. Dion (Eds.), Multiculturalism and Social Cohesion: Potentials and Challenges of Diversity (pp. 1-47). Dordrecht: Springer Netherlands.

Roccas, S., \& Schwartz, S. H. (1993). Effects of intergroup similarity on intergroup relations. European Journal of Social Psychology, 23, 581-595.

Rosseel (2012). lavaan: An R Package for Structural Equation Modeling. Journal of Statistical Software, 48, 1-36.

Scheepers, D., Saguy, T., Dovidio, J. F., \& Gaertner, S. L. (2014). A shared dual identity promotes a cardiovascular challenge response during interethnic interactions. Group Processes \& Intergroup Relations, 17, 324-341.

Seery, M. D. (2011). Challenge or threat? Cardiovascular indexes of resilience and vulnerability to potential stress in humans. Neuroscience \& Biobehavioral Reviews, 35, 1603-1610.

Selfhout, M., Denissen, J., Branje, S., \& Meeus, W. (2009). In the eye of the beholder: Perceived, actual, and peer-rated similarity in personality, communication, and friendship intensity during the acquaintanceship process. Journal of Personality and Social Psychology, 96, 1152-1165.

Sherwood, A., Allen, M. T., Fahrenberg, J., Kelsey, R. M., Lovallo, W. R., \& van Doornen, L. J. 
(1990). Methodological guidelines for impedance cardiography. Psychophysiology, 27, $1-23$.

Shrout, P. E., \& Fleiss, J. L. (1979). Intraclass correlations: Uses in assessing rater reliability. Psychological Bulletin, 86, 420-428.

Stephan, W. G., \& Stephan, C. W. (1985). Intergroup anxiety. Journal of Social Issues, 41, 157175.

Stephan, W. G., \& Stephan, C. W. (2000). An integrated threat theory of prejudice. In S. Oskamp (Ed.), Reducing prejudice and discrimination, (pp. 23-45). Mahwah, NJ, US: Lawrence Erlbaum Associates, Inc.

Strang, A. J., Funke, G. J., Russell, S. M., Dukes, A. W., \& Middendorf, M. S. (2014). Physiobehavioral coupling in a cooperative team task: Contributors and relations. Journal of Experimental Psychology: Human Perception and Performance, 40, 145-158.

Struch, N., \& Schwartz, S. H. (1989). Intergroup aggression: Its predictors and distinctness from in-group bias. Journal of Personality and Social Psychology, 56, 364-373.

Tajfel, H. E. (1978). Differentiation between social groups: Studies in the social psychology of intergroup relations. London: Academic Press.

Vorauer, J. D. (2005). Miscommunications surrounding efforts to reach out across group boundaries. Personality and Social Psychology Bulletin, 31, 1653-1664.

Vorauer, J. D. (2006). An information search model of evaluative concerns in intergroup interaction. Psychological Review, 113, 862-886.

Vorauer, J. D., \& Cameron, J. J. (2002). So close, and yet so far: Does collectivism foster transparency overestimation? Journal of Personality and Social Psychology, 83, 1344. 
Vorauer, J. D., \& Sakamoto, Y. (2006). I thought we could be friends, but... Systematic miscommunication and defensive distancing as obstacles to cross-group friendship formation. Psychological Science, 17, 326-331.

Waters, S. F., West, T. V., \& Mendes, W. B. (2014). Stress contagion: Physiological covariation between mothers and infants. Psychological Science, 25, 934-942.

West, T. V., Magee, J. C., Gordon, S. H., \& Gullett, L. (2014). A little similarity goes a long way: The effects of peripheral but self-revealing similarities on improving and sustaining interracial relationships. Journal of Personality and Social Psychology, 107, $81-100$.

Wilhelm, F. H., Grossman, P., \& Roth, W. T. (1999). Analysis of cardiovascular regulation. Biomedical Sciences Instrumentation, 35, 135-140.

Wright, S. C., Aron, A., \& Tropp, L. R. (2002). Including others (and groups) in the self: Selfexpansion and intergroup relations. In J. P. Forgas \& K. D. Williams (Eds.), The social self: Cognitive, interpersonal and intergroup perspectives (pp. 343-363). Philadelphia: Psychology Press. 
Table 1

Physiological Synchrony Model

\begin{tabular}{|c|c|c|c|c|c|c|c|c|}
\hline Fixed Effects & $b$ & $b_{\text {lower }}$ & $b_{\text {upper }}$ & $S E$ & $d f$ & $\begin{array}{c}t- \\
\text { value }\end{array}$ & $\begin{array}{c}p- \\
\text { value }\end{array}$ & $r$ \\
\hline Intercept & -6.92 & -8.99 & -4.86 & 1.05 & 332 & -6.60 & $<.001$ & -0.34 \\
\hline Participant Sympathetic Reactivity & 0.08 & -0.05 & 0.20 & 0.06 & 332 & 1.17 & 0.243 & 0.06 \\
\hline Participant Similarity Prime & 0.45 & -1.60 & 2.50 & 1.02 & 49 & 0.45 & 0.658 & 0.06 \\
\hline Participant Sympathetic Reactivity $\times$ Participant Similarity & & & & & & & & \\
\hline Prime & -0.15 & -0.26 & -0.04 & 0.06 & 332 & -2.60 & 0.010 & -0.14 \\
\hline Variance of Random Effects & $\sigma^{2}$ & $\sigma_{\text {lower }}^{2}$ & $\sigma_{\text {upper }}^{2}$ & & & & & \\
\hline Intercept (Dyad) & 4.97 & 0 & 141495.24 & & & & & \\
\hline Participant Sympathetic Reactivity (Dyad) & 0.08 & 0.03 & 0.21 & & & & & \\
\hline Intercept (Participant) & 88.91 & 48.19 & 164.05 & & & & & \\
\hline Residual & 9.28 & 7.91 & 10.88 & & & & & \\
\hline
\end{tabular}

Note: $b$ is the unstandardized slope, $b_{\text {lower }}$ and $b_{\text {upper }}$ are the lower and upper bounds of the slope's $95 \%$ confidence interval, $S E$ is the standard error of the slope, $d f$ are the degrees of freedom for that effect, $t$-value tests whether $b$ is different from zero, $p$-value reflects the probability of $t$-value given the slope is zero, and $r$ is a correlation coefficient reflecting the partial effect size. Similarity prime was coded with Similarity $=1$, Dissimilarity $=-1$. 
Table 2

Correlations, Means, and Standard Deviations for MSEM Variables

\begin{tabular}{|c|c|c|c|c|c|c|c|c|c|c|c|c|c|}
\hline & $\mathrm{a}$ & $\mathrm{b}$ & $\mathrm{c}$ & $\mathrm{d}$ & $\mathrm{e}$ & $\mathrm{f}$ & $\mathrm{g}$ & $\mathrm{h}$ & $\mathrm{i}$ & $\mathrm{j}$ & $\mathrm{k}$ & 1 & $\mathrm{~m}$ \\
\hline a. Partner Positive Affect & 1 & & & & & & & & & & & & \\
\hline b. Participant Positive Affect & 0.6 & 1 & & & & & & & & & & & \\
\hline c. Partner Laughter & 0.48 & 0.26 & 1 & & & & & & & & & & \\
\hline d. Participant Laughter & 0.26 & 0.48 & 0.41 & 1 & & & & & & & & & \\
\hline e. Partner Smiles & 0.55 & 0.26 & 0.87 & 0.32 & 1 & & & & & & & & \\
\hline f. Participant Smiles & 0.26 & 0.55 & 0.32 & 0.87 & 0.31 & 1 & & & & & & & \\
\hline g. Partner Sociability & 0.46 & 0.25 & 0.78 & 0.36 & 0.76 & 0.31 & 1 & & & & & & \\
\hline $\begin{array}{l}\text { h. Participant Sociability } \\
\text { i. Observed Interest in }\end{array}$ & 0.25 & 0.46 & 0.36 & 0.78 & 0.31 & 0.76 & 0.31 & 1 & & & & & \\
\hline $\begin{array}{l}\text { Contact } \\
\text { i. Self-reported Interest in }\end{array}$ & 0.32 & 0.39 & 0.49 & 0.78 & 0.48 & 0.72 & 0.48 & 0.83 & 1 & & & & \\
\hline Contact & 0.12 & -0.01 & 0.11 & 0.11 & 0.08 & 0.11 & 0.23 & 0.04 & 0.2 & 1 & & & \\
\hline k. Email Exchange & 0.14 & 0.00 & 0.08 & 0.09 & 0.17 & 0.12 & 0.23 & 0.01 & 0.12 & 0.5 & 1 & & \\
\hline 1. Similarity Prime & -0.21 & -0.15 & -0.25 & -0.16 & -0.28 & -0.09 & -0.23 & -0.18 & -0.22 & 0.05 & 0.1 & 1 & \\
\hline m. SNS Covariance & 0.31 & 0.31 & 0.19 & 0.19 & 0.19 & 0.19 & 0.21 & 0.21 & 0.15 & -0.05 & -0.10 & -0.34 & 1 \\
\hline Mean & 47.86 & 47.86 & 4.30 & 4.30 & 4.77 & 4.77 & 4.57 & 4.57 & 4.63 & 5.35 & 0.66 & -0.05 & 0.14 \\
\hline $\mathrm{SD}$ & 36.80 & 36.80 & 1.57 & 1.57 & 1.47 & 1.47 & 1.23 & 1.23 & 1.09 & 0.85 & 0.48 & 1 & 0.25 \\
\hline
\end{tabular}




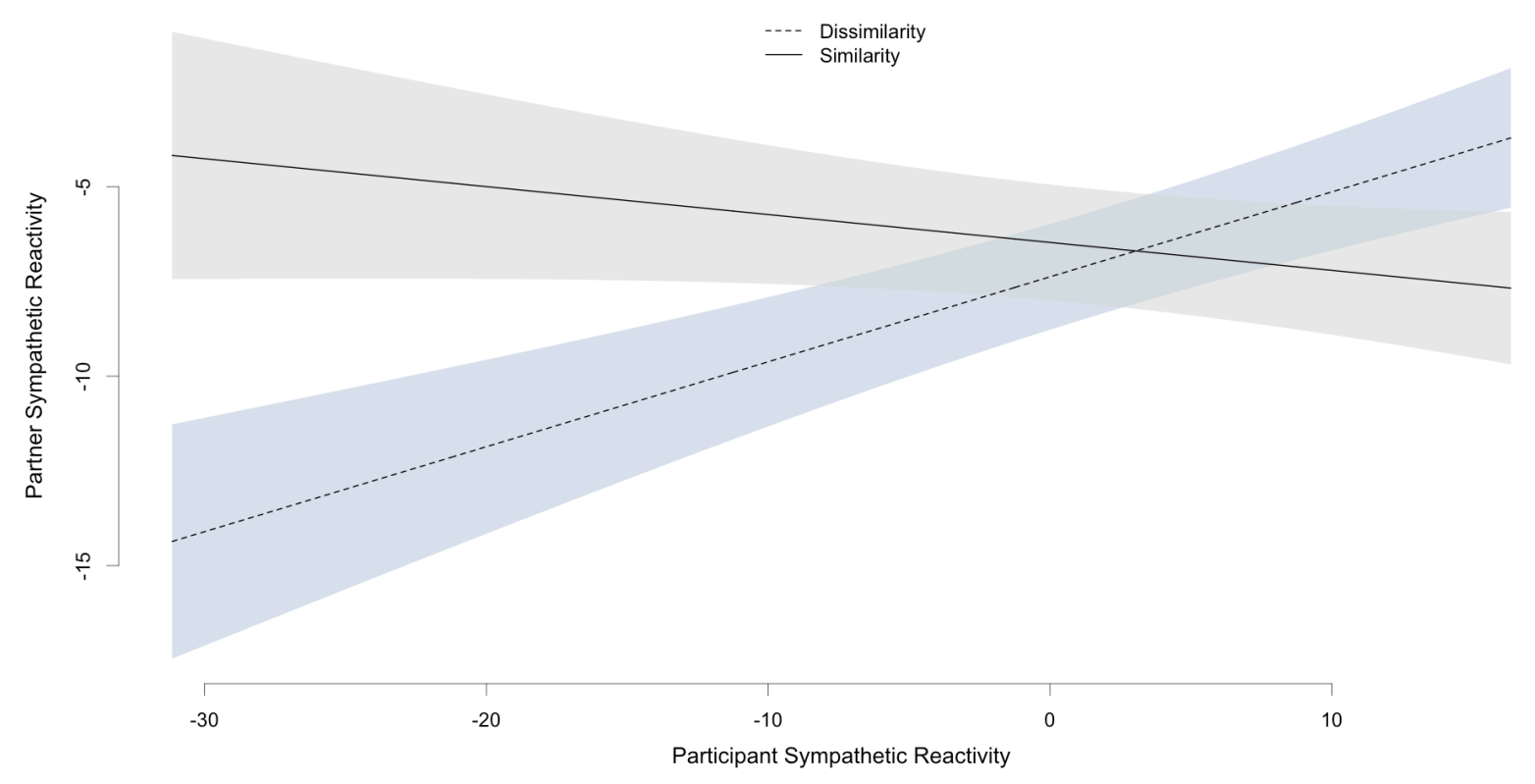

Figure 1. The effect of the intergroup similarity on physiological synchrony of the sympathetic nervous system. Both axes represent changes in sympathetic reactivity (i.e., pre-ejection period) in milliseconds. Smaller values reflect greater sympathetic reactivity. Plotted values are estimated from the model. Shaded areas represent one standard error above and below estimated values. The dashed line represents participants primed with intergroup dissimilarity and the solid line represents participants primed with intergroup similarity. 


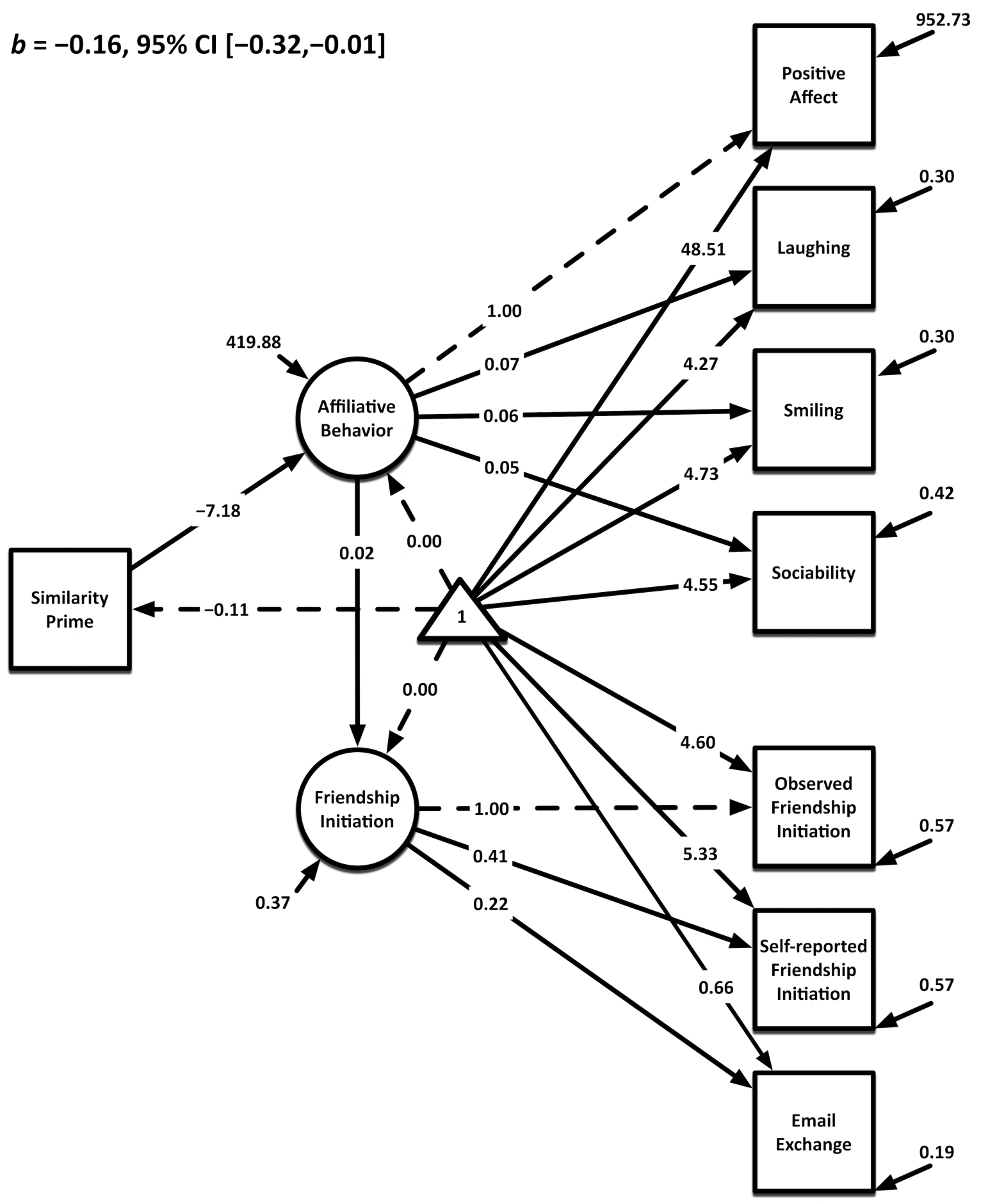

Figure 2. Multilevel Structural Equation Model representing the indirect effect of similarity on participant friendship initiation through partner affiliative behavior. Paths are unstandardized, but statistically significant paths are represented with solid lines and statistically non-significant paths or paths that were fixed are represented with dashed lines. Each latent variable has one indicator variable whose path was set to 1 for model identification. Variances are represented with lone single-headed arrows. 


\section{Footnotes}

${ }^{1}$ This study included a manipulation of intergroup conflict/harmony that had no effect on any of our outcome measures. The conflict/harmony manipulation was performed by priming participants' perceptions with essay prompts similar to the similarity/dissimilarity manipulation. We do not elaborate on the rationale behind including conflict as a manipulation because we want to focus the introduction on the results being reported and we do not discuss it after this footnote.

${ }^{2}$ A technological failure led to the loss of essay data from one participant.

${ }^{3}$ We were interested in physiological synchrony of the sympathetic nervous system for theoretical and historical reasons. However, ECG and ICG can be used to extract other physiological measures that are relevant to social interaction generally and intergroup interactions specifically (i.e., activity of the parasympathetic nervous system and physiological patterns of challenge and threat). We thus conducted exploratory analyses to examine the effect of the similarity prime on physiological synchrony of the parasympathetic nervous system and challenge and threat that are reported in the Supplemental Materials.

${ }^{4}$ Given that raters and participants answered the same questions to assess friendship initiation, we also compared how much their responses correlated and whether there were mean differences between rater-observed and self-reported friendship initiation. To assess their correlation, we used a 2-level multilevel model where self-reported friendship initiation was predicted by raterobserved friendship initiation, with a random intercept for each dyad. Indeed, observed friendship initiation was moderately related to self-reported friendship initiation, $b=0.25,95 \%$ CI $[0.05,0.46], S E=0.10, t(52)=2.47, p=.017, r=.32$. To assess mean-differences, we used a 3-level model where reports of friendship initiation were regressed on a within-target variable of 
reporter $($ rater $=-1$, self $=1$ ), with a random intercept for both the target and the dyad and a random slope for reporter. There was a moderate mean-level difference such that friendship initiation was rated as higher by the participants than by the raters, $b=0.34,95 \%$ CI $[0.21,0.48]$, $S E=0.07, t(105)=4.94, p<.001, r=.43$.

${ }^{5}$ The intraclass correlation coefficient derived for both Levels 2 and 3 of the model suggested that the individual level explained a large part of the variance in partner sympathetic reactivity, $I C C=.69$, and the dyad level explained a small amount of this variance, $I C C=.23$, thus multilevel modeling was appropriate for these data.

${ }^{6}$ Physiological synchrony is a dyadic process, however, most of our measures were focused at the individual level. Thus, we wanted to manipulate our independent variables at that level too. Furthermore, randomizing the similarity prime at the level of the individual avoids known issues regarding random assignment at higher levels in MLM, which is more commonly known as a cluster randomized design (Raudenbush, 1997).

${ }^{7}$ Larger degrees of freedom for estimates of physiological synchrony are a result of the mixed design involving repeated measures of PEP reactivity over the 5 minutes of the social interaction. 